\title{
Heart failure in patients of acute ST elevation myocardial infarction with impaired renal function
}

\author{
Authors \\ Dr Md. Habibur Rahman ${ }^{1 *}$, Prof. (Dr) Md. Faruque ${ }^{2}$, Dr Md. Sirajum Munir ${ }^{3}$, \\ Dr Azizul Karim 4 \\ ${ }^{1}$ Assistant Professor, MD, Cardiology, US Bangla Medical College, Dhaka \\ ${ }^{2}$ Professor, MD, Cardiology, Anwar Khan Modern Medical College, Dhaka \\ ${ }^{3}$ Assistant Professor, MD, Cardiology, Kushtia Medical College, Kushtia \\ ${ }^{4}$ Assistant Professor, MD, Cardiology, National Institute of Cardiovascular Diseases, Dhaka \\ *Corresponding Author
}

Dr Md. Habibur Rahman

\begin{abstract}
Introduction: Ischemic heart disease (IHD) is a common cardiac disorder and significant cause of mortality and morbidity worldwide. Effective risk stratification is integral to the management of patients with acute coronary syndromes and associated chronic kidney disease may adversely affect acute STEMI outcome.

Objective: in this study our main goal is to detect the incidence of heart failure in patients of acute STEMI patients with impaired renal function.

Method: This prospective study was done in the cardiology department of cardiology in NICVD after approval of protocol for one year.

Results: For these purpose 100 patients of STEMI diagnosed by clinical, biochemical and ECG criteria were included in the study. After getting serum creatinine level, eGFR was calculated and if it is $<60 \mathrm{ml} / \mathrm{min}$ then the patient was selected for the study. Among the 100 patients inferior MI was 34\%, anterior MI was $20 \%$, extensive anterior MI was $12 \%$, anteroseptal MI was $18 \%$, Inferolateral MI was $10 \%$, lateral MI was $2 \%$, high lateral MI was $3 \%$ and anteroinferior was $1 \%$. Of these patients heart failure was found in $21 \%$ patients.

Conclusion: From this study it can be concluded that impaired renal function among MI patients has an adverse outcome. Early detection of renal impairment is necessary to avoid increased mortality and morbidity.
\end{abstract}

Keywords: STEMI, Renal Impairment, Heart failure.

\section{Introduction}

Coronary heart disease is a worldwide health epidemic. Worldwide 30 percent of all deaths can be attributed to cardiovascular disease of which more than half are caused by coronary heart disease. Globally of those dying from cardiovascular disease, 80 percent are in developing countries ${ }^{1}$. In 2001 it was estimated that worldwide coronary artery disease was responsible for 11.8 per cent of all death in low income countries ${ }^{2}$. Incidence of coronary artery disease in Bangladesh has increased from 3.3 per 
thousand to 14 per thousand from the year 1975 to $1985^{3}$. Acute STEMI is defined by at least two of the followings in which typical ECG changes is a must and any one either typical chest pain of cardiac origin or significantly raised troponin I level ${ }^{4}$.In STEMI cigarette smoking, male gender and a family history of cardiovascular and renal disease are associated with adverse prognosis in young patients, whereas dyslipidaemia, hypertension and diabetes mellitus are associated with adverse prognosis in the elderly ${ }^{5}$.
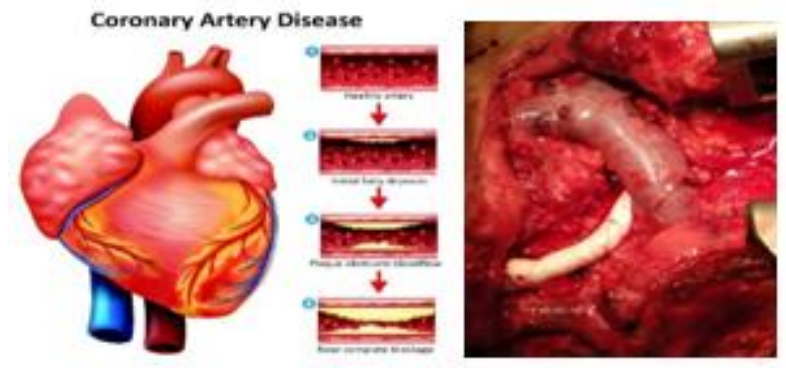

Figure-1: Coronary heart disease and during surgery

Impaired renal function is manifested by decreased GFR. Decreased GFR is measured by increased serum creatinine or more preciously by reduced creatinine cleareance $(<60 \mathrm{ml} / \mathrm{min})$. It is an independent risk factor for CAD outcome ${ }^{6-7}$. Mild renal impairment is associated with an increased risk of coronary artery disease and stroke, suggesting that cardiovascular disease may develop early in the course of renal dysfunction ${ }^{8-9}$. So it is a time demand to do a study to see the incidence of heart failure in patients of acute STEMI patients with impaired renal function.

\section{Objective \\ General Objective}

To identify the Incidence of heart failure in patients of acute ST elevation myocardial infarction with impaired renal function

\section{Methodology \\ Study Type \\ $>$ This was a prospective observational study.}

\section{Study Period and Place}

$>$ This study was conducted at National Institute of Cardiovascular Diseases (NICVD) within a period of one year from January 2011 to December 2011 after the approval of ethical review committee. For this purpose, 100 patients of acute ST elevation MI with impaired renal function were included in this study.

\section{Inclusion Criteria}

$>$ acute STEMI within twelve hours after the onset of chest pain who are eligible for thrombolysis

$>$ eGFR $\quad<60 \mathrm{ml} / \mathrm{min} \quad$ (Cockcroft-Gault formula), Voluntary given consent to participate in the study.

\section{Method}

A patient with diagnosed case of MI or his/her legal guardian was thoroughly informed about the aims, objectives and detailed procedure of the study before examination. He/She was encouraged for voluntary participation and allowed freedom to withdraw from the study whenever he/she liked even after participation. From all eligible subjects after getting consent clinical history was taken and clinical examination was done to elicit findings related to MI. Related investigations like blood sugar and serum creatinine were done. Blood was collected within two hours after admission of the patient in the hospital. If the patients calculated eGFR is less than $60 \mathrm{ml} / \mathrm{min}$ and ECG criteria confirms the acute STEMI then he/she was included in the study as case. Patients were followed up till discharge with special attention to serum creatinine and development of other complications. The researcher did not influence the ongoing hospital treatment. The endpoint of the study was sudden cardiac death or rise of serum creatinine double of the baseline value. All relevant data was noted in the pre tested data sheet. All data were checked and rechecked to avoid error. All investigations were done in National Institute of Cardiovascular Diseases (NICVD). 


\section{Data Analysis}

by using computer bases software SPSS19(Statistical Package for Social Science). Discrete or qualitative variables was analyzed by Chi-squared test and continuous variables will be analyzed by $\mathrm{t}$ - test. $\mathrm{P}$ value will be considered as statistically significant when it is less than 0.05 .

\section{Results}

In table-1 shows Distribution of age between the study groups $(\mathrm{n}=100)$ where Most of the patients (67\%) were in between 41-60 years in this study. The following table is given below:

Table 1: Distribution of age between the study groups $(\mathrm{n}=100)$

\begin{tabular}{|l|c|c|}
\hline \multirow{2}{*}{ Age in Groups } & \multicolumn{2}{|c|}{$(n=100)$} \\
\cline { 2 - 3 } & Frequency & $\%$ \\
\hline$<40$ yrs & 14 & 14.0 \\
\hline $41-50$ yrs & 32 & 32.0 \\
\hline $51-60$ yrs & 35 & 35.0 \\
\hline $61-70$ yrs & 19 & 19.0 \\
\hline$>70$ yrs & 0 & 0.0 \\
\hline
\end{tabular}

In figure-2 shows distribution of gender $(\mathrm{n}=100)$ where among 100 patients, 77 were male and 23 were female. The following figure is given below:

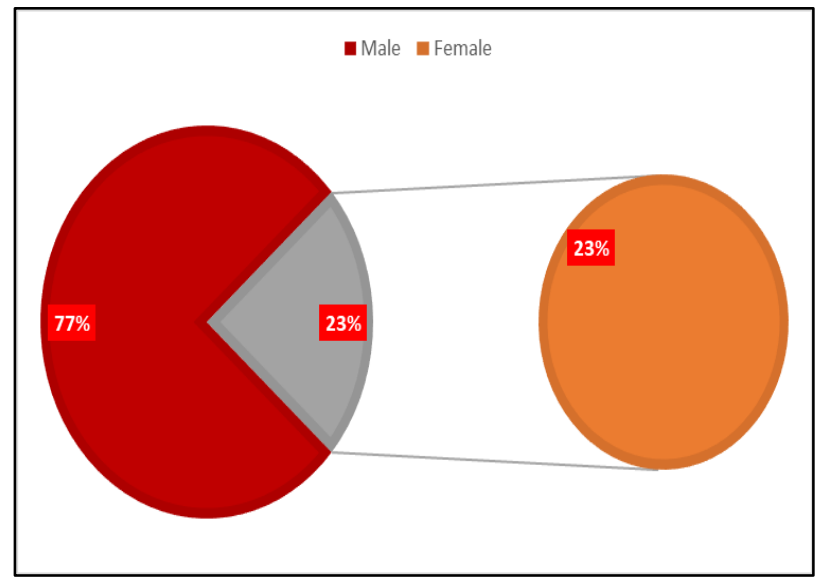

Figure 2: Distribution of gender $(n=100)$

In figure-3 shows Examination findings where the incidence of heart failure was $21 \%$.Among the heart failure patients raised JVP was found in $12 \%$, gallop rhythm was $10 \%$ and basal crepitation was $21 \%$. The following figure is given below:

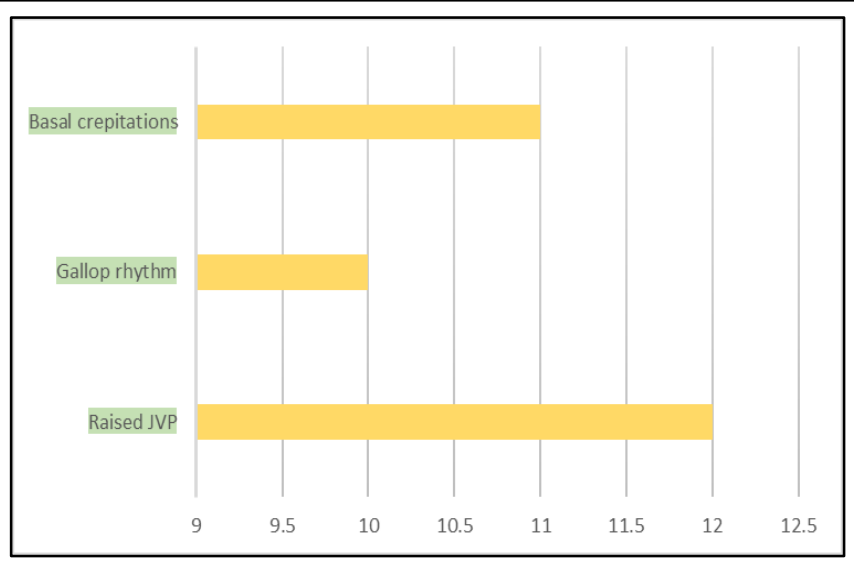

Figure-3: Examination findings

In table-2 shows Distribution of investigation findings where patients LVEF (\%) was found $50.82 \pm 9.99$ (Mean \pm SD), random blood sugar was found in $222.82 \pm 72.16$, serum creatinine was found in $1.62 \pm 0.37$. The following table is given below:

Table 2: Distribution of investigation findings (n $=100$ )

\begin{tabular}{|l|c|}
\hline \multirow{2}{*}{ Investigations } & $(\mathrm{n}=100)$ \\
\cline { 2 - 2 } & Mean $\pm \mathrm{SD}$ \\
\hline LVEF $(\%)$ & $50.82 \pm 9.99$ \\
\hline RBS $(\mathrm{mg} / \mathrm{dl})$ & $222.82 \pm 72.16$ \\
\hline LDL C & $210 \pm 23.8$ \\
\hline Serum creatinine & $1.62 \pm 0.37$ \\
\hline
\end{tabular}

In table-3 shows Distribution of types of myocardial infarction among the study population where In patients Inferior MI was 34\%,anterior MI was $20 \%$,Extensive anterior MI was $12 \%$, Antero-septal MI was $18 \%$, Infero-lateral MI was $10 \%$, Lateral MI was $02 \%$, High lateral MI was $03 \%$, Anteroinferior MI was $01 \%$.

Table 3: Distribution of types of myocardial infarction among the study population

\begin{tabular}{|l|c|c|}
\hline \multirow{2}{*}{ Types of MI } & \multicolumn{2}{|c|}{ Total $(\mathrm{n}=100)$} \\
\cline { 2 - 3 } & Frequency & $\%$ \\
\hline Inferior & 34 & 34.0 \\
\hline Anterior & 20 & 20.0 \\
\hline Extensive Anterior & 12 & 12.0 \\
\hline Antero-septal & 18 & 18.0 \\
\hline Infero-lateral & 10 & 10.0 \\
\hline Latera & 2 & 2.0 \\
\hline High lateral & 3 & 3.0 \\
\hline Anteroinferior & 1 & 1.0 \\
\hline
\end{tabular}


In table-4 shows Incidents of heart failure patients stratified by eGFR $(n=100)$ where Out of 21 heart failure patients, eGFR was $60-30 \mathrm{ml} / \mathrm{min}$ in 11patients, $30-15 \mathrm{ml} / \mathrm{min}$ in 6 patients, $<15 \mathrm{ml} / \mathrm{min}$ in 4 patients. The following table is given below:

Table 4: Incidents of heart failure patients stratified by eGFR $(n=100)$

\begin{tabular}{|c|c|c|c|c|c|c|c|}
\hline & \multicolumn{6}{|c|}{ eGFR } & \multirow[t]{3}{*}{ P-value } \\
\hline & \multicolumn{2}{|c|}{$\begin{array}{c}60-30 \\
(n=71)\end{array}$} & \multicolumn{2}{|c|}{$\begin{array}{c}30-15 \\
(n=22)\end{array}$} & \multicolumn{2}{|c|}{$\begin{array}{c}<15 \\
(n=7)\end{array}$} & \\
\hline & $\mathbf{N}$ & $\%$ & $\mathbf{n}$ & $\%$ & $\mathbf{N}$ & $\%$ & \\
\hline Heart Failure $(\mathrm{n}=21)$ & 11 & 15.4 & 6 & 27.2 & 4 & 57.8 & $0.026^{\mathrm{s}}$ \\
\hline
\end{tabular}

\section{Discussion}

Acute myocardial infarction (AMI) is one of the major health problems all over the world and the coronary artery thrombosis is the leading cause of it ${ }^{10}$.In the developing country like Bangladesh, urbanization is taking place at a rapid pace that is responsible for change in the lifestyle which adversely affects the metabolism thereby causing a large increase in the number of diabetic patients ${ }^{11}$.

In the present study, among 100 patients male was $77 \%$ and female was $23 \%$. Male to female ratio was 3.34:1. A higher prevalence of ischemic heart disease in male than female has been reported in a study from England. Thus the present results are in agreement that male population is more prone to STEMI which may be linked to genetic/ hormonal difference.

The present study showed among the 100 patients most of the patients were in age group 51-60 years (35\%) next to which was $41-50$ years $(32 \%)$. Mean \pm SD of age was $52.84 \pm 8.40$ years.

Regarding the evaluation of risk factors of STEMI hypertension was found in $61 \%$, smoker was $52 \%$, dyslipidemia was present in $78 \%$, DM was in $31 \%$, sedentary life style was found in $23 \%$ patients obesity was common among $23 \%$ of total patients and family history of IHD was found in $24 \%$ of patients. The results of present study with reference to risk factors were similar to those published earlier that type 2 diabetic patients were more hypertensive than non-diabetic. $48 \%$ patients were found hypertensive in the diabetic group where as only $36 \%$ patients were found hypertensive in non diabetic group. All of the above findings are consistent with the earlier study $^{12}$.

Of the 100 patients in inferior MI was 34\%, anterior MI was $20 \%$, extensive anterior MI was $18 \%$, anteroseptal MI was $12 \%$, Inferolateral MI was $10 \%$, lateral MI was $2 \%$, high lateral MI was $3 \%$ and anteroinferior was $1 \%$. The present study found non-significant difference in the site of infarction among all patients. Inferior and anterior infarction were found commonest. In some studies, lateral infarction was found common in diabetic group ${ }^{\mathbf{1 3}}$. But in the present study it was not found which may be due to small size.

Regarding analysis of complications and outcome Mean \pm SD of hospital stay of the study patients was $4.51 \pm 0.77$ days. Left ventricular ejection fraction was found in $50.82 \pm 9.99 \%$ and random blood sugar was found in $222.82 \pm 72.16 \mathrm{mg} / \mathrm{dl}$. Among the 100 patients heart failure was found in $21 \%$.This findingare as expected from the patients with STEMI ${ }^{14}$.

Regarding eGFR and different complications more were found with low eGFR. We have shown that, in patients admitted with STEMI and across each STEMI grouping, creatinine clearance is an important independent predictor of hospital mortality. In our study 4 cases died with low eGFR. A $10 \mathrm{ml} / \mathrm{min}$ decrease in creatinine clearance had the same adverse impact on hospital death rates as a 10-year increase in age. Increased renal dysfunction was observed more often in elderly (aged $>65$ years) and female patients. It is well known that renal function decreases with age, 
and women are considerably older than men when they are admitted with an STEMI, which may partially explain the predominance of women with reduced renal function ${ }^{15}$.

Increased creatinine concentrations are common in older patients and are independently associated with an increased risk of death, cardiovascular disease, and congestive heart failure. It can be said that the increased risk of death begins with mildly elevated concentrations of serum creatinine.

\section{Conclusion}

From the present study it can be concluded that increased incidence of heart failure occurs among MI patients with impaired renal function. Early detection of renal impairment is necessary to avoid increased mortality and morbidity.

\section{References}

1. Kim MC, Kini AS, Fuster V. Definitions of acute coronary syndromes. In: Fuster V, O'Rourke RA, Walsh RA, Poole-Wilson P. Eds. Hurst's the Heart. $12^{\text {th }}$ ed. New York, USA: McGraw Hill; 2008.1311.

2. Yang EH, Gersh BJ, O'Rourke RA. ST segment elevation myocardial infarction. In: Fuster V, O'Rourke RA, Walsh RA, Poole-Wilson P. Eds. Hurst's the Heart. $12^{\text {th }}$ ed. New York, USA :McGraw Hill; 2008. 1375.

3. Malik A. Congenital and acquired heart disease: A survey of 7062 person. Bangladesh Med Res Bull 1976; 11: 11519.

4. Kim MC, Kini AS, Fuster V. Definitions of acute coronary syndromes: Non-ST elevation myocardial infarction. In: Fuster V, O'Rourke RA, Walsh RA, Poole-Wilson P. Eds. Hurst's the Heart. $12^{\text {th }}$ ed. New York, USA: McGraw Hill; 2008.1314.

5. Abbott JD, Ahmed HN, Vlachos HA, Selzer F, Williams DO. Comparison of outcome in patients with ST-elevation versus non-ST-elevation acute myocardial infarction treated with percutaneous coronary intervention. Am J Cardiol 2007; 100:193-195.

6. Wannamethee SG, Shaper AG, Perry IJ. Serum creatinine concentration and risk of cardiovascular disease: A possible marker for increased risk of stroke. Stroke 1997; 28:557-63.

7. Alcorn HG, Wolfson SK Jr, Sutton-Tyrrell K. Risk factors for abdominal aortic aneurysms in older adults enrolled in the cardiovascular health study. Arterioscler Thromb Vasc Biol 1996;16:963-70.

8. Pahor M, Shorr RI, Somes GW. Diureticbased treatment and cardiovascular events in patients with mild renal dysfunction enrolled in the systolic hypertension in the elderly program. Arch Intern Med 1998; 158:1340-5.

9. Culleton BF, Larson MG, Wilson PW. Cardiovascular disease and mortality in a community-based cohort with mild renal insufficiency. Kidney Int 1999;56:2214-9.

10. Ramachandan A, Snehalata C, Satyavani K, Vijay V. Impaired fasting glucose and impaired glucose tolerance in urban population in India. Diabet Med 2003;20(3):220-4

11. Chowdhury MAR, Hossain AKMM. A comparative study on the effects of streptokinase between diabetic and nondiabetic myocardial infarction patients. Bangladesh J Pharmacol2008;3:1-7

12. Culie V. Acute myocardial infarction: Differing preinfraction and clinical features according to infarct site and gender. Int J Cardiol 2003; 90(2-3):189-96

13. Thiele H. Comparison of pre-hospital combination fibrinolysis plus facilitated percutaneous coronary intervention in acute myocardial infarction. Eur Heart J. 2005; 26: 1956-63.

14. Kim MC, kini AS, Fuster V. Definitions of acute coronary syndromes: ST-segment elevation myocardial infarction. In: Fuster V, O'Rourke RA, Walsh RA, Poole- 
Wilson P. Eds. Hurst's the Heart. $12^{\text {th }}$ ed.

New York, USA: McGraw Hill; 2008.

1316.

15. Antopinto JJ, Fox KAA, Goldberg RJ, Budaj A, Piñero A, Avezum A, et al. on behalf of the GRACE Investigators* Creatinine clearance and adverse hospital outcomes in patients with acute coronary syndromes: findings from the global registry of acute coronary events (GRACE) Heart 2003;89:1003-1008. 